\title{
WIND ANALYSIS OF TALL BUILDING IN DUHOK CITY USING COMPUTATIONAL FLUID DYNAMIC (CFD)
}

\author{
SHIREEN T. SAAdullah and JAMEs H. Haido \\ Dept. of Civil Engineering, College of Engineering, University of Duhok, Kurdistan Region-Iraq
}

\begin{abstract}
Present article is devoted to study wind flow around concrete buildings. Computational fluid dynamic (CFD) model was performed in three dimensional (3D) commercial packages ANSYS CFX 14.0. utilizing finite volume technique to predict the wind pressures on tall buildings using specific boundary conditions. RNG k- $\varepsilon$ turbulence model was used in the program to consider the wind turbulence. Current numerical approach was verified by comparison the outcomes with experimental wind tunnel tests. This valid CFD model was applied in the simulation of the wind analysis for Rixos Hotel which is located in Duhok City, Iraq. Analysis outputs of Rixos building were compared to those calculated by some international building codes; reasonable agreement was observed with using ASCE 2010 code. It is concluded that the stagnation point at which the wind streamline velocity comes to rest is located at $2 / 3$ of the building height above the ground surface.
\end{abstract}

KEYWORDS: tall buildings, finite volume method, computational fluid dynamic, RNG $\mathrm{k}-\varepsilon$ turbulence model, wind pressure on buildings

\section{INTRODUCTION}

$\mathbf{B}^{\mathrm{a}}$ asically, wind is caused by the motion of air from high pressure region toward low pressure zone with equal elevation and different densities. Wind nature is always turbulent in the atmospheric boundary layer and described in mean velocity component and fluctuating turbulence component (Dyrbye and Hansen 1997). Roughness of the ground surface play great role on the regional wind velocity. There is slight influence of the surface roughness on wind with increasing in height at which the wind velocity increases accordingly (Taranath 2012). At specific height (gradient height $\mathrm{Z}_{\mathrm{g}}$ ) over ground, the motion of air is no longer affected by surface obstruction (Tamura and Kareem, 2013). This height can be given as a function of surface roughness and wind velocity gradient. Concerning with building analysis, wind loading is a complicated phenomenon due to various flow situations arise from interaction of wind and structure (Mendis et al. 2007). There are three main types of wind actions which interesting in buildings design namely prevailing winds, local winds, and seasonal winds (Tamura and Kareem 2013). In purpose of wind loads determination, the characteristics of seasonal and prevailing winds are grouped together, while those of local winds are studied separately. The properties of wind relevant to structural analysis are wind velocity with height (velocity profile), wind turbulence, vortex shedding, and statistical probability of wind and dynamic nature of wind-structure interaction (Taranath, 2012). Thus, wind load pressures and structural responses are some of the main factors that effect on the design of high-rise buildings. Nowadays, buildings are built with high resistance light materials in contrast to old tall buildings which were constructed with heavy massive masonry block. The light materials lead to induce a problematic lateral wind force on the modern buildings due to decrease in the structural rigidity (Parv et al. 2012). Computational Fluid Dynamic (CFD) is a utilization of applied mathematics, computational programming and physics to imagine how a gas or liquid streams influence objects based on the Navier-Stokes equations. Recently, due to the development of the computer computational methods such as Finite Element Method (FEM), Finite Difference Method (FDM) and Finite Volume Method (FVM), they are mostly used as CFD solvers (Jeong and Seong 2014, Haleem 2015). The computational wind engineering which is a part of CFD has been advanced quickly since the three last decades to investigate the interaction between airflow and buildings. This evolution proposes an 
alternative technique for practical applications such as expensive wind tunnel testing (Sevalia et al. 2012). Moreover, the CFD technique is preferred in analysis because of its easiness and precision in calculation of air flow around the buildings with different shapes.

Paterson and Apelt (1986) studied the effects of wind flow around a three dimensional building by numerical approach. The simulation was done by PHOENICS computer program. Steady NavierStokes equation has been solved with using of $k-\varepsilon$ turbulence model in simulation by these programs. A power-law velocity profile was employed for description of incident wind. Four flows have been considered in the study and the outcomes of simulation were compared with the full scale wind tunnel data. According to this comparison, it was indicated that there were good agreement among the outputs that confirm the validation of wind flow by numerical simulation.

An investigation has been launched by Stathopoulos and Zhou (1995) to compute wind pressures on flat roofs of low and high rise buildings. The Reynold average Navier stokes equation with the standard $\mathrm{k}-\varepsilon$ turbulence model has been used in modeling. Wind blowing was assumed to be in normal and oblique directions. The evaluation of wind pressure was made for three different distances $d_{p}$ from the roof edges to the center of first grid line. Authors concluded that the roof surface can be divided into two subregions based on computed pressure namely region highly based on $d_{p}$ and region independent on this distance. In addition, it was found that the oblique direction of wind blowing influenced more than the normal direction in pressure calculation.

Nguyen et al. (2006) investigated the dynamic torsional behavior of rectangular shape high rise building model under wind actions. The numerical approach based on ANSYS CFX 10.0 was used in the analysis with three different side ratios. The wind velocity of $10 \mathrm{~m} / \mathrm{s}$ at the reference height of $125 \mathrm{~cm}$ was used at the inlet boundary conditions. The same scaled model of wind tunnel was used with constant height of $75 \mathrm{~cm}$, constant width of $10 \mathrm{~cm}$ and various depths of 10,30 and $100 \mathrm{~cm}$. The results of numerical approach were compared with those for wind tunnel given by Cheung and Melbourne (1992) in terms of the dynamic torsional moment. It was concluded that the differences in wind velocity profile and its intensity have great effect on simulation.

Computational Fluid Dynamic approach has been used by Yujun et al. (2008) to predict air flow and wind loading over a tower building. Turbulence model has been selected as the Peking University Model Atmospheric Environmental (PUMA). The experimental test was carried out in the University of Peking with the cross sectional dimensions of $2 \times 3 \mathrm{~m}$. Pitot tube anemometers were applied to measure the wind velocity and wind pressure on the surface of the building. Finally, comparison has been made between the numerical and experimental results. Good agreement between numerical and experimental outcomes was observed in terms of pressure distribution and wind flow on building. The researchers recommended using the differential scheme of turbulence in the analysis.

Dagnew et al. (2009) were used the Commonwealth Advisory Aeronautical Council (CAARC) building model with dimensions of $30 \times 45 \times 183 \mathrm{~m}$ in wind analysis. The study was based on numerical method with focusing on Reynolds Averaged Navier Stokes equations (RANS) and Large Eddy Simulation (LES) turbulence model. Wind pressures on tall buildings were evaluated and compared with the wind tunnel measurements for that building. The renormalized group RNG $\mathrm{k}-\varepsilon$ turbulence model gave better agreement with boundary layer wind tunnel result compared to standard k- $\varepsilon$. Good matching has been observed between LES numerical results and the experimental outcomes on the windward face. On the other hand, the agreement deteriorated slightly at the sidewalls and improved at the lee-ward wall.

The effect of wind on Milad Telecommunication Tower with height of $436 \mathrm{~m}$ constructed in Iran was investigated by Yahyai et al. (2011). In this study, CFD technique with both standard $\mathrm{k}-\varepsilon$ and large eddy simulation turbulence models were used. The model with the length scale of 1:100 was utilized in the computational domain. At used inflow boundary condition, the velocity profile was depended on ASCE (2010) which is consistent with the experimental velocity profile simulated in wind tunnel. The results of Yahyai et al. (2011) were compared with available experimental data. They concluded that LES with a dynamic sub grid scale model (SGS) was produced more precise results than other models for mean and dynamic (fluctuating) wind loads on 
the tower. Moreover, it was noticed that standard $\mathrm{k}-\varepsilon$ method after modification can give reasonable outcomes. Indication has been given as that the feature of the flow around buildings can be captured using the CFD method.

Ramponi and Blocken (2012) presented a study on a cross ventilation of wind flow for four different building configurations with CFD approach. Three dimensional steady RANS method was employed with the SST k-w turbulence model. The authors were focused on providing a validation study on the coupling of indoor to outdoor windflow by comparing the computational result with wind tunnel data. The effects of physical diffusion number (a) in turbulent kinetic energy equation have been taken into account. It was found out that the best choice of $\mathrm{a}$ is 1.0 to reach good agreement with experimental measurements. The study on the distribution of pressure coefficients of wind on the windward and leeward for a building face with and without balconies was performed by Montazeri and Blocken (2013). The results of CFD methods were compared with wind tunnel data of Chand et al. (1998). The comparison results showed well agreement at normal wind direction for the case of building with balconies.

Behrouzi et al. (2014) investigated the flow around two tall buildings. The numerical simulation was based on Fluent software for simulating the wind flow. Three types of turbulence models were adopted such as standard $\mathrm{k}-\varepsilon$, renormalized group RNG $\mathrm{k}-\varepsilon$ and realizable $\mathrm{k}-\varepsilon$. The outcomes were compared with previous wind tunnel data. The comparison clarified that the standard $k-\varepsilon$ could not produce the reattachment length on the top of buildings.
However, RNG k- $\varepsilon$ and realizable $k-\varepsilon$ have capability of producing the reasonable reattachment length on the top and behind of buildings.

According to aforementioned literature survey, it is noticed that the CFD has not been extensively employed especially for irregular tall buildings analysis that located in areas (such as north of Iraq) where there is no specific code for wind analysis. Thus, further investigations on this topic are considered essential. In present work, CFD was performed in ANSYS CFX 14.0 to study the wind flow and pressures on Duhok Rixos Hotel which is located in Duhok city, Iraq. Furthermore, best code of analysis was selected with respect to the numerical analysis outputs.

\section{METHODOLOGY}

Current analysis was carried out in two stages namely verification of the validity for the used CFD environment by comparison with an experimental tunnel test data and application of the valid CFD for wind analysis of a building in Duhok city.

\subsection{Governing Equations for Wind within Atmospheric Boundary Layer (ABL)}

The governing equations in fluid dynamics can be applied to wind flow through Atmospheric Boundary Layer $(\mathrm{ABL})$. Liquid or wind flows in CFD codes are governed by partial differential equations which are based on the conservation laws for mass, energy and momentum. The following expressions are applied for three dimensional, steady and incompressible flows with constant viscosity.

$\frac{\partial \rho}{\partial t}+\frac{\partial(\rho u)}{\partial x}+\frac{\partial(\rho v)}{\partial y}+\frac{\partial(\rho w)}{\partial z}=0$

Continuity equation

$\frac{\partial \rho u_{i}}{\partial t}+\frac{\partial\left(\rho u_{i} u_{j}\right)}{\partial x_{j}}=-\frac{\partial P}{\partial x_{i}}+\frac{\partial}{\partial x_{j}}\left[2 \mu S_{i j}\right]$

Momentum equation

Where

$\mathrm{u}, \mathrm{v}$ and $\mathrm{w}=$ velocities of air in $\mathrm{x}, \mathrm{y}$ and $\mathrm{z}$ directions respectively

$\mathrm{u}_{\mathrm{i}}, \mathrm{u}_{\mathrm{j}}=$ velocity components in $\mathrm{m} / \mathrm{s}$

$\mathrm{i}=1,2,3$

$\mathrm{j}=1,2,3$

$\rho=$ Density of air in $\mathrm{kg} / \mathrm{m} 3$

$\mathrm{P}=$ Pressure of air in $\mathrm{Pa}$

$\mu=$ The dynamic viscosity in $\mathrm{Pa}$

$\mathrm{t}=$ time

$S_{i j}=\frac{1}{2}\left(\frac{\partial u_{i}}{\partial x_{j}}+\frac{\partial u_{j}}{\partial x_{i}}\right) \quad$ Velocity strain rate tensor 


\subsection{Present Turbulence Model in CFD}

RNG $\mathrm{k}-\varepsilon$ turbulence model is based on a mathematical technique of renormalization group which is proposed by Yakhot et al. (1992). This model is utilized to renormalize the Navier-Stokes equations and to put the effects of smaller scales of motion into account. In contrast to the standard $\mathrm{k}-\varepsilon$ turbulence model, the eddy viscosity is determined from a single turbulence length scale.
The main difference between the standard $\mathrm{k}-\varepsilon$ and RNG $\mathrm{k}-\varepsilon$ models is that the latter includes extra terms in the turbulent dissipation rate $\varepsilon$-equation. The equation for RNG $k-\varepsilon$ model is applied for effective viscosity flow, which has low Reynolds number, effects (Piradeepan 2002). The equations of transport can be given as follows (Piradeepan 2002):

a. Transport equation for kinetic energy $\mathrm{k}$ :

$\rho \frac{d k}{d t}=\frac{\partial}{\partial x_{i}}\left(\alpha_{k} \mu_{e f f} \frac{\partial k}{\partial x_{i}}\right)+P_{k}-\rho \varepsilon$

b- Transport equation for dissipation rate $\varepsilon$ :

$\rho \frac{d \varepsilon}{d t}=\frac{\partial}{\partial x_{i}}\left(\alpha_{\varepsilon} \mu_{e f f} \frac{\partial \varepsilon}{\partial x_{i}}\right)+C_{1 \varepsilon} \frac{\varepsilon}{k} P_{k}-C_{2 \varepsilon}{ }^{*} \rho \frac{\varepsilon^{2}}{k}$

where,

$\mu_{e f f}=\mu+\mu_{t}$

$\mu_{t}=\rho C_{\mu} \frac{k^{2}}{\varepsilon}$

where

$C_{\mu}=0.0845, \alpha_{k}=\alpha_{\varepsilon}=1.39, C_{1 \varepsilon}=1.42$ and $C_{2 \varepsilon}=1.68$

The significant difference (Eq. 5) between both Standard and RNG k $-\varepsilon$ turbulence models is calculated from the near wall turbulence data as hereunder:

$C_{2 \varepsilon}^{*}=C_{2 \varepsilon}-\frac{C_{\mu} \rho \eta^{3}\left(1-\eta / \eta_{0}\right)}{1+\beta \eta^{3}}$

where,

$\eta=\frac{k}{\varepsilon} \sqrt{2 S_{i j} \cdot S_{i j}}$

$\eta_{0}=4.377$

$\beta=$ Wall damping, needs to be applied to ensure the viscosity $=0.01$,

For the current endeavor, RNG k- $\varepsilon$ model is utilized for simulation of wind over buildings Present simulation was performed in the ANSYS CFX 14.0 program which is based on the finite volume technique to discretize Navier-stokes equation by utilizing a mesh. Finite volumes are employed to conserve relevant amounts such as continuity, energy and momentum (ANSYS-CFX
2011). In steady state flow, the first order schemes with the RNG k- $\varepsilon$ turbulence model were used in presentwork for both space and time discretization. In reality the mesh is three dimensional objects, but for describing the control volume structures the typical two dimensional mesh was used as illustrated in the Figure (1). All fluid properties and variables for solution are stored at the nodes. 


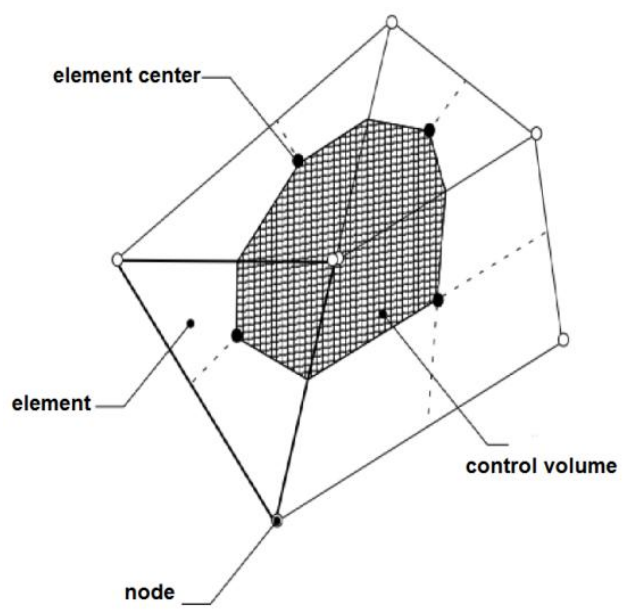

Fig. (1): Description of control volume around the node (ANSYS-CFX 2011)

\subsection{Verification of Present CFD}

Current finite volume analysis in ANSYS CFX 14.0 was examined by comparison its outputs with actual wind tunnel test data for Blue Tower which is located in Dubai, UAE. This tower is also known as the HHHR tower (Figure 2) which is a super tall skyscraper. The building is constructed for residential purpose with height of $317 \mathrm{~m}$. Blue Tower is the fourth tallest residential building in the world. The flowchart of CFD modeling methodology for this building in ANSYS CFX is depicted in Figure (3). Geometry model of HHHR building (Figure 4) is provided in this program. Basically, there are no restrictions for computing the required domain size of wind around the building (Baetke et al. 1990). Many investigators were determined this size by the trial and error process (Baskaran and Kashef 1996).The domain size can be found with utilizing the multipliers of characteristic height $(\mathrm{H})$ of structure (Tominaga et al. 2008).

It was recommended that the lateral and the top boundaries should be set as $5 \mathrm{H}$ or more away from the building. The distance between the inlet boundary and the building should be the same of that enclosed by a smooth floor in the wind tunnel or at least $5 \mathrm{H}$ away from the building. The outflow boundary should be set as $10 \mathrm{H}-15 \mathrm{H}$ apart from the building wall. This distance must be large enough to prevent the reflection of fluid streams, which may cause unusual pressure field around the model (Tominaga et al. 2008; Franke et al. 2007). Blockage ratio (i.e ratio of the frontal area of the model to the computational domain cross section) is usually less than $3 \%$ as proposed by (Baetke et al. 1990). In the current study, the domain size was adopted as $20 \mathrm{H} \times 6 \mathrm{H} \times 10 \mathrm{H}$ in the longitudinal $\mathrm{x}$, vertical $\mathrm{y}$ and lateral $\mathrm{z}$ directions respectively. The computational grids of aforementioned domain were implemented by dividing into small control volumes to form a mesh to control the resolution of flow $(\mathrm{Hu}$ and Wang 2005). Franke et al. (2007) were proposed that both hexahedral and tetrahedral meshes can be used in CFD applications for wind flow around buildings.

In addition, they were recommended a minimum of 10 cells per building side to be utilized for the initial grid resolution. The computational domain in present modeling was automatically meshed by using three-dimensional unstructured (i.e. tetrahedron element shape) method. Furthermore, mesh (Figure 5) size around the model is selected to be very fine using face sizing. The vertical section near the ground was manually altered via inflation layer. Mesh size of $2 \mathrm{~m}$ was adopted in the current simulation for the inflation layer which complies with sand grain roughness height of the ground surface (Blocken et al. 2007). The physical properties of the air flow, such as viscosity, density, reference pressure and temperature were introduced. Then, Boundary conditions were defined to include the effect of environment which has been cut off by the computational domain as depicted in Figure (6). Owing to the Navier-Stokes equations, it is required to have an initial guess to begin the iterations for steady state simulation. The faster solution can be gained by providing best initial conditions. Moreover, the introduced data for initial condition should be compatible with the inlet velocity component. The boundary 
conditions used in the simulation are described as follows:

\section{a- Inlet Boundary Condition}

There are two important sets of wind velocity profile that identify the inlet boundary condition, namely logarithmic law and power law methods. Both approaches are combining surface roughness and wind speed to consider the influence of surface friction on the wind velocity. The logarithmic law was employed in the current work. Wind velocity and turbulence profiles (i.e. defined by the turbulence kinematic energy and dissipation rate) for CFD simulation was adopted based on Richards and Norris formula (Richards and Norris 2011), as hereunder:

$U(z)=\frac{U_{*}}{K} \ln \left(\frac{Z}{z_{O}}\right)$

$K=\frac{U_{*}^{2}}{\sqrt{C_{\mu}}}$

$\varepsilon(z)=\frac{U_{*}^{3}}{\kappa \cdot z}$

where,

$\mathrm{U}_{*}=$ friction velocity which is usually computed from a specified reference speed $\left(\mathrm{u}_{\mathrm{r}}\right)$ at a reference height (building height) as:

$$
U_{*}=\frac{K \cdot U_{r}}{\ln \left(\frac{Z_{r}}{Z_{O}}\right)}
$$

$U(z)=$ mean wind speed

$K=$ Turbulent kinetic energy

$\varepsilon(z)=$ Turbulent dissipation energy

$\kappa=$ Von Karman's constant $=0.4$

$C_{\mu}=$ constant $=0.09$

$Z_{O}=$ Roughness length $($ rough terrain $)=0.2 \mathrm{~m}($ ASCE 2010; AS/NZS 2011)

\section{b- Bottom or Ground Surface}

The ground surface was defined as no slip rough face with depending on the equivalent sand grain roughness $\mathrm{K}_{\mathrm{s}}$ expression as (Blocken et al. 2007):

$$
K_{S}=\frac{E \cdot Z_{O}}{C_{S}}
$$

where,

$\mathrm{K}_{\mathrm{S}}=$ sand grain roughness height

$\mathrm{E}=$ empirical constant $=9.793$

$\mathrm{C}_{\mathrm{S}}=$ Roughness constant for ANSYS CFX $14=0.3$

$\mathrm{Z}_{0}=$ Roughness length

$$
K_{s} \cong 30 * Z_{O}
$$

c- Top and Lateral Surfaces

For the Lateral and top surfaces of the computational domain, symmetric boundary condition was used as proposed by Tominaga et al. (2008) .

d- Outflow and Building Walls

The outlet with zero gradient pressure was used for the downstream of the computational domain. Building surface boundary was defined by smooth wall functions basing on $(\mathrm{Hu}$ and Wang 2005).

The steady state simulation was considered to attain convergence criteria when the value of relative residual error reached to 10-5. First order differentiation was utilized for the momentum and turbulence equations. The total computational time need for each simulation was based on many factors such as type of turbulence model, number of grid, type of elements used in the meshing. For 
the present model of building, the computational time of analysis was about 4 hour. The details of meshing for HHHR Tower which is shown in (Figure 5) as follows:

The multi techniques such as (patched independent method with inflation layer and body size) are used.

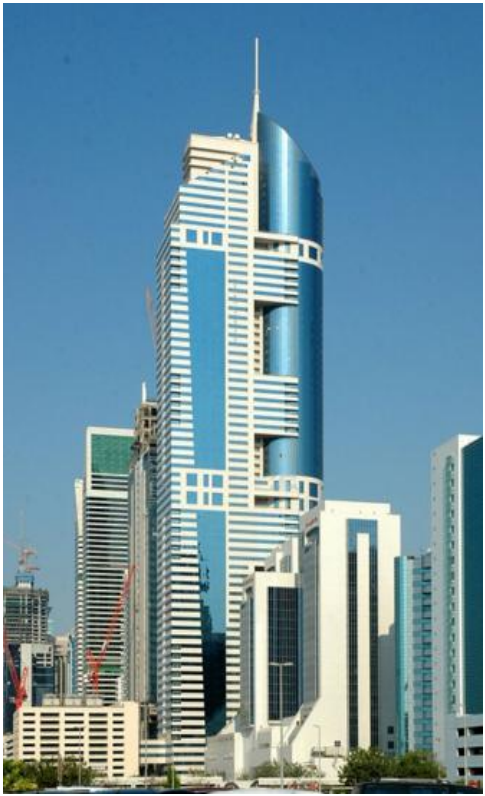

Fig. (2) HHHR Tower in Dubai (Skyscraper centre, 2010)

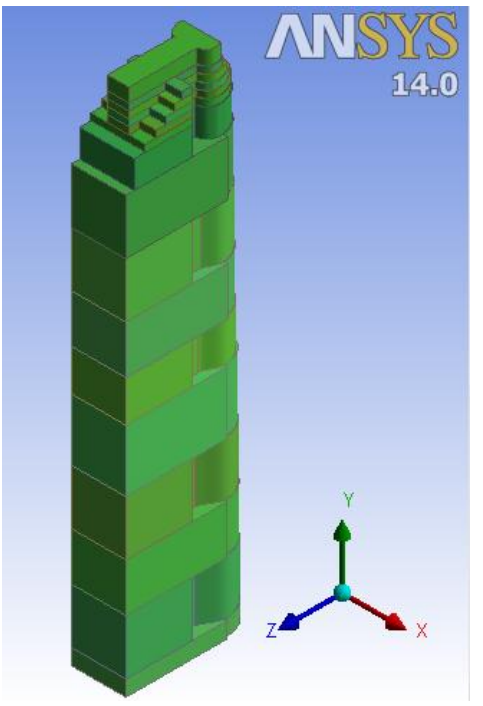

Fig. (4): Geometry model of Blue Tower
(Number of nodes $=1732572$, Number of elements=7758890)

Inflation layer, (first layer height $=2 \mathrm{~m}$, Number of layers $=5$ )

Face sizing around building is used $=0.6 \mathrm{~m}$

Geometrical Modeling:

Define geometry \& boundaries location

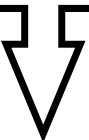

Grid Generation: Divide the geometry into small computational cells

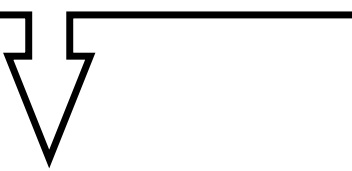

Defining Domain and Models:

Add turbulence RNG $\mathrm{K}-\varepsilon$ mode

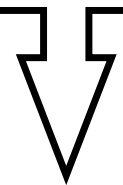

Set Wind Properties: Density, viscosity, etc.

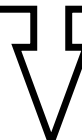

Set the Proposed Boundaries \& Inlet Conditions: The initial conditions for building, inlet, outlet, and conditions at the walls

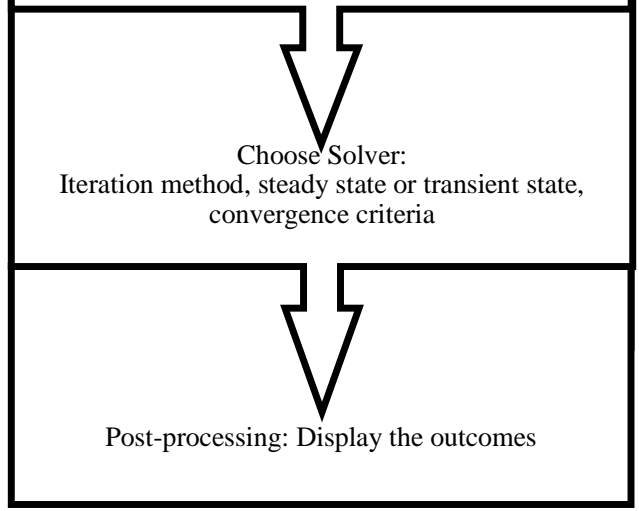

Fig. (3): Present CFD simulation process with ANSYS CFX 


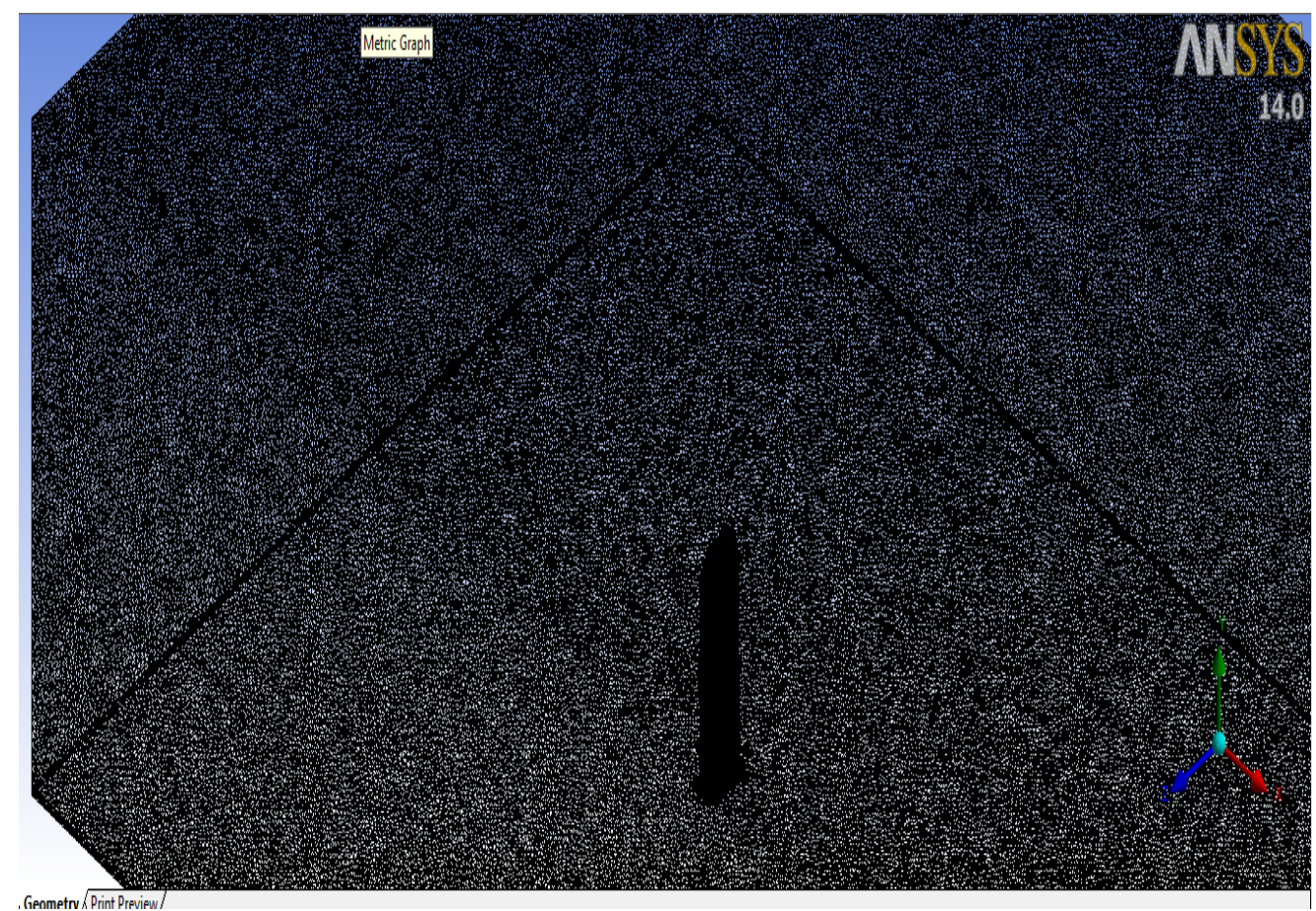

Fig. (5): Domain meshing for Blue Tower

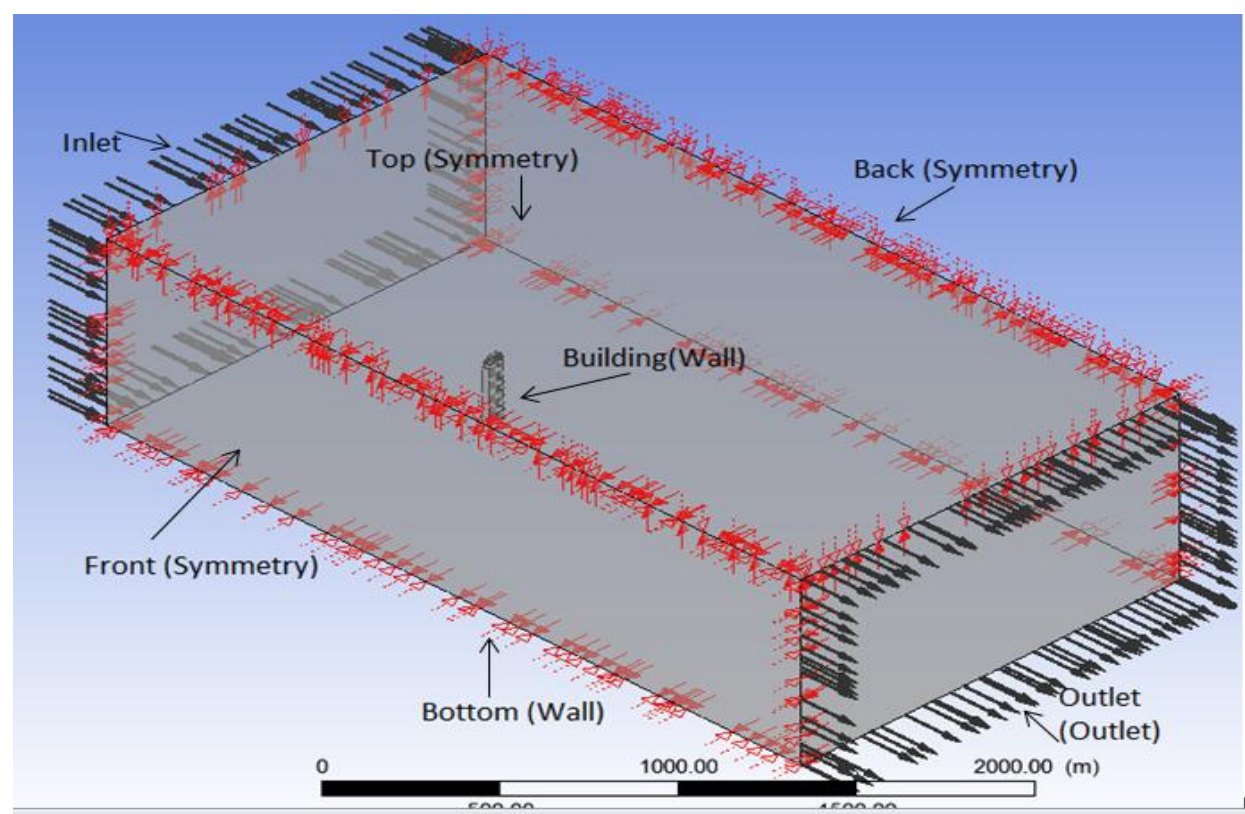

Fig. (6): Boundary conditions of HHHR Tower model within domain

\subsection{CFD Model for Rixos Hotel Building}

The Rixos Hotel building (Figure 7) which was built with reinforced concrete at height of $80 \mathrm{~m}$ and located in Duhok city was selected in present work as a case study. It was modelled in ANSYS
CFX 14.0 following up the same procedure for HHHR Tower modeling. Accordingly, the geometry model, computational domain, meshing and boundary condition of the model within the domain are provided as shown in Figures (8-10). 


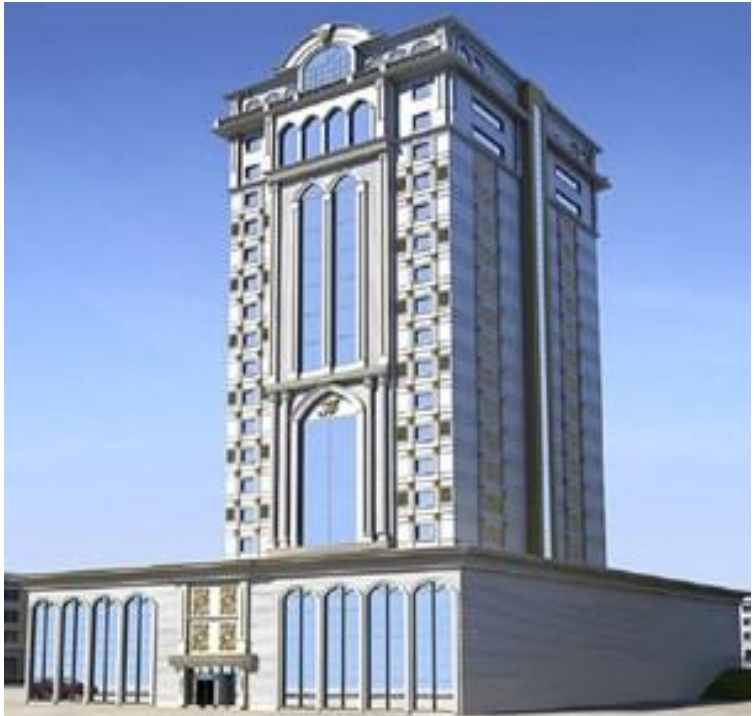

Fig. (7): Rixos Hotel building (Duhok Rixos Hotel 2012)
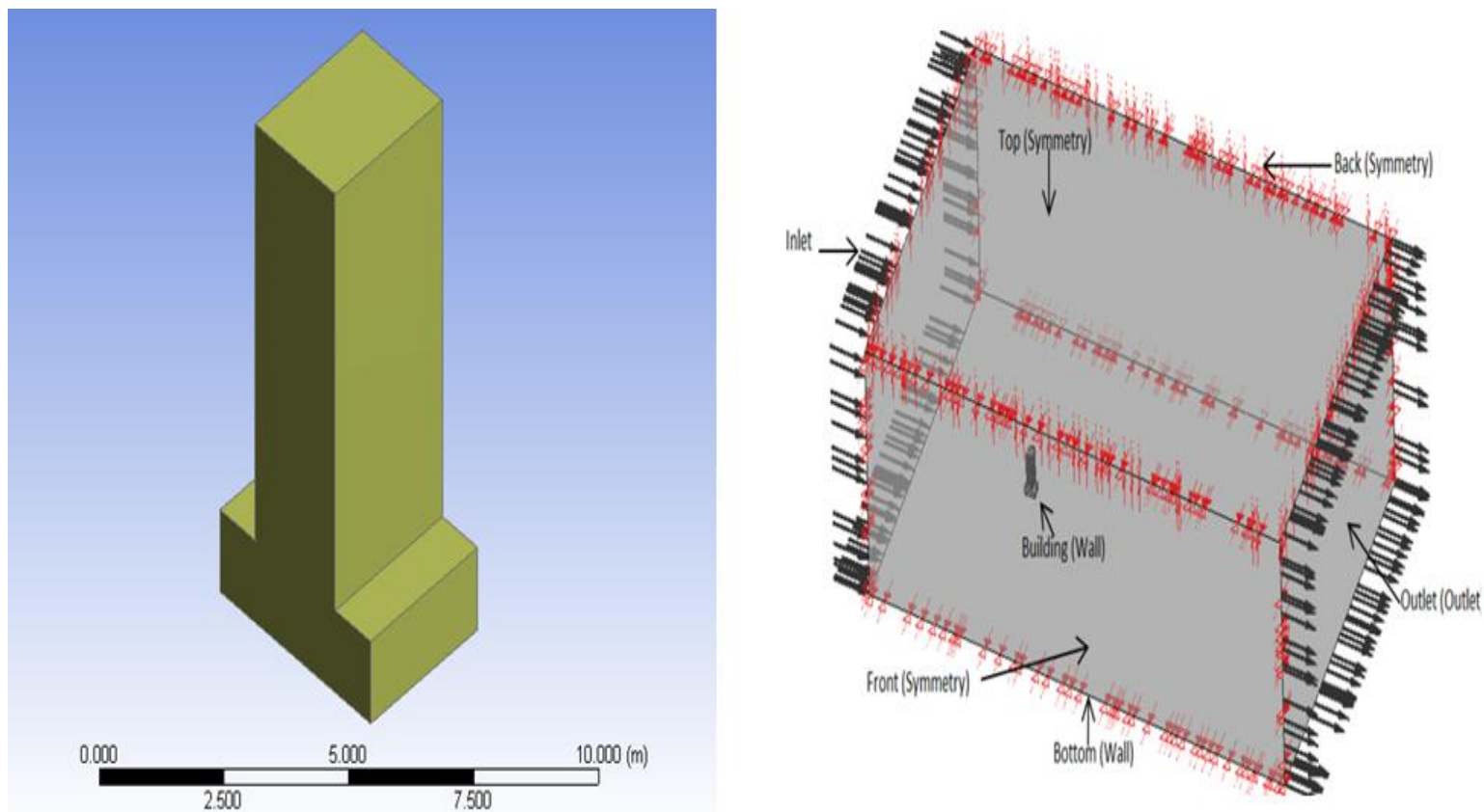

Fig. (8): Geometry model of Rixos Hotel building

Fig. (9): Boundary conditions of Rixos Hotel model within domain 


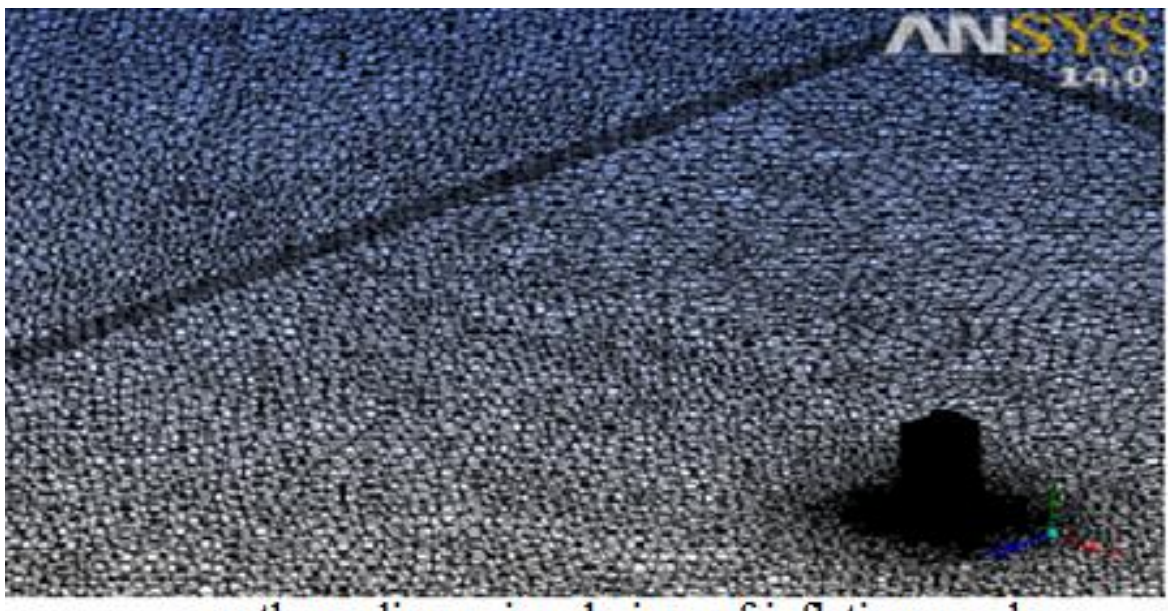

a- three.dimensional view of inflation mesh

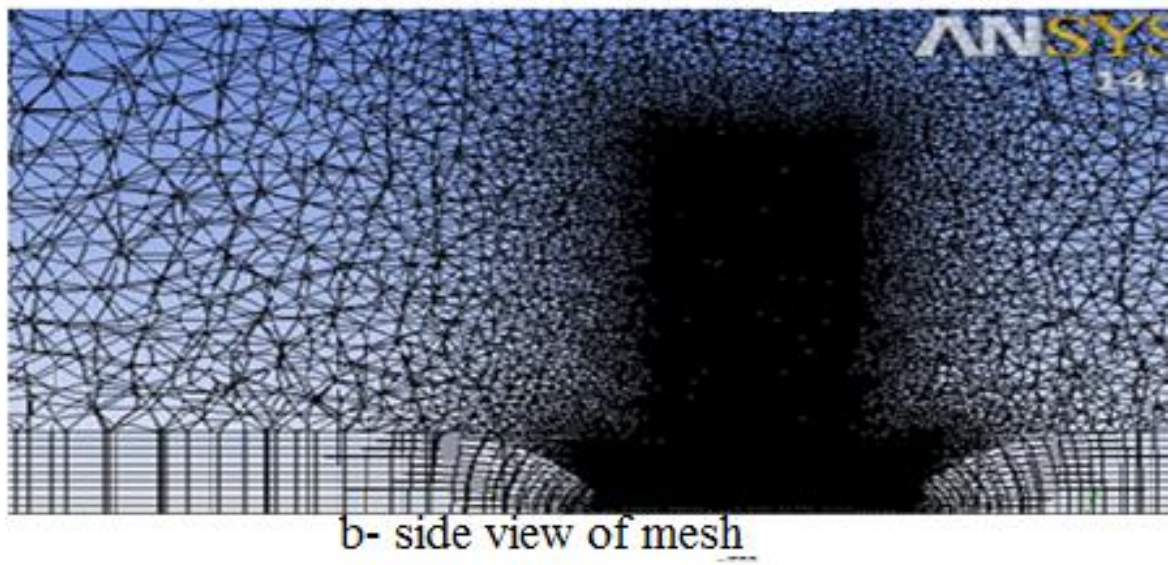

Fig. (10): Domain meshing of Rixos Hotel Building

\subsection{Solver Setting and Computational Time}

The steady state simulation was considered to attain convergence criteria when the value of relative residual RMS (root mean square) error reached 10-5. High resolution advection scheme was used. First order differentiation was utilized for the momentum and turbulence equations. Iteration number equal to 500, the Auto Timescale was used with factor 1.0. The $(\mathrm{Y}+)$ was checked in the domain equal to 2.05 and it is within specification The total computational time needed for each simulation was based on many factors such as type of turbulence model, number of grid, type of elements used in the meshing. For the present model of Rixos building, the tetrahedral mesh with 1632053 nodes and 8719106 elements and RNG $\mathrm{k}-\varepsilon$ turbulence model were used. The computational time of current work was about 3-5 hr. In order to decrease this time, it was done with 10 CPUs in parallel computation at double precision.

\section{WIND ANALYSIS OUTCOMES}

Present computational analysis results are displayed in two forms such as CFD verification and application outputs.

\subsection{Current CFD Verification Outcomes}

The speed of the applied wind around Blue tower was found graphically in terms of counter line (Figure 11) using present CFD. It is observed that the wind speed increases with the height above the ground surface. Accurate prediction of the wind speeds is essential for correct estimation of surface wind pressures. In order to investigate the variation of the wind pressures on surfaces of building, certain points on building surfaces were choice. The probe function was used in current CFX simulation. (Figure 12) presents the comparison between the pressures of the applied wind on the building found by current CFD modelling and wind tunnel data of Farquhar and Galsworthy (Farquhar and Galsworthy 2008). Good matching can be noticed in this graph between present numerical outcomes and 
experimental data. Furthermore, largest variations are seen to be occurred at the points near the corners and on the bottom row of the windward side. These differences are produced by the approximate description of the turbulent intensity such as turbulent kinetic energy and turbulent dissipation energy at these locations. (Figure 13) shows the pressures distribution contours on the wind ward and leeward faces of irregular Blue Tower building. It is observed that the characteristics of the pressure contour are different for the windward and leeward faces of building. The pressure is increased with the height at the windward face. However, the pressures on the leeward face are approximately equivalent at all heights.

The validity of present CFD simulation was checked statistically in SPSS Statistics 20 program. Thus, histograms were got with abscissa of the ratio for numerical CFD outcomes to those for experimental wind tunnel test data. The ordinate of the histogram represents the number of repeating of the values on $\mathrm{x}$-axis. (Figure 14 and Figure 15) show the histograms of pressures distribution around Blue Tower with consideration of $0 \mathrm{o}$ and $90 \mathrm{o}$ of wind directions. Mean, standard deviation and sample size $(\mathrm{N})$ are shown on each figure. The percentages of matching between CFD and experimental results are $90 \%$ and $71 \%$ for pressures on the windward face with 00 and 900 respectively. Ferziger (1990) was recommended that $25 \%$ of difference between numerical and experimental methods is considered acceptable; while Stathopoulos and Baskaran (1996) were stated that $30 \%$ is reasonable too. Accordingly, present CFD outputs are regarded suitable and agreeable in comparison to wind tunnel test measurements. In general, it is demonstrated that the current ANSYS CFX 14.0 model can provide acceptable predictions of wind pressure for irregular super tall building.

Moreover, Figure (16) shows the streamlines of wind velocity in vertical plane at centre of building. These streamlines describe many other features of flow namely separation zone in the upstream corner (point $\mathrm{F}$ ), recirculation zone (point I), head of the arch vortex (point G), and the reattachment line (point $\mathrm{H}$ ).Wind flow at two thirds of the tower height comes to rest and forms the stagnation point. This characteristic is displayed in Figure (18) by red circle. It occurs at height of $200 \mathrm{~m}$ for Blue building. This result is complying with Blocken et al (2011) whose stated that the stagnation point locates within $60 \%-70 \%$ of the building height.

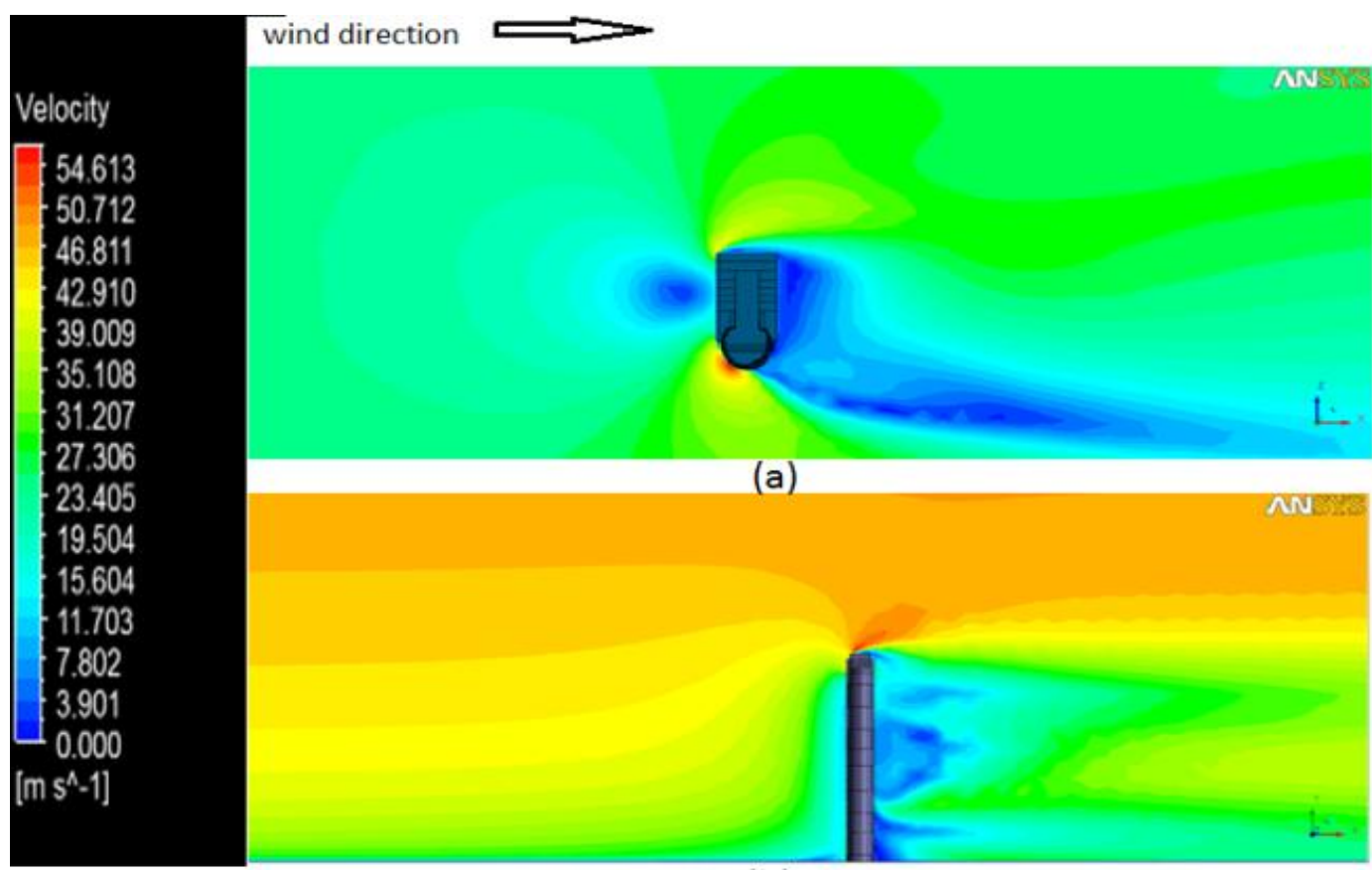

(b)

Fig. (11): Distribution of wind speeds contour around Blue Tower:

(a) Horizontal plane at $5 \mathrm{~m}$ high; (b) Vertical plane 


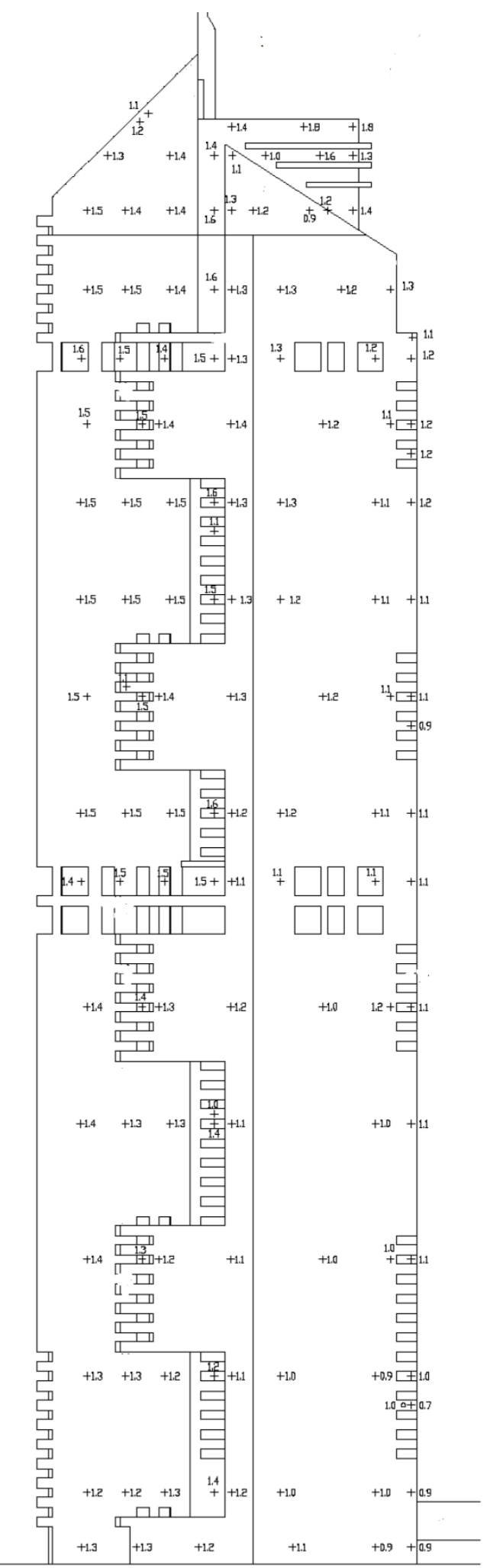

(a)

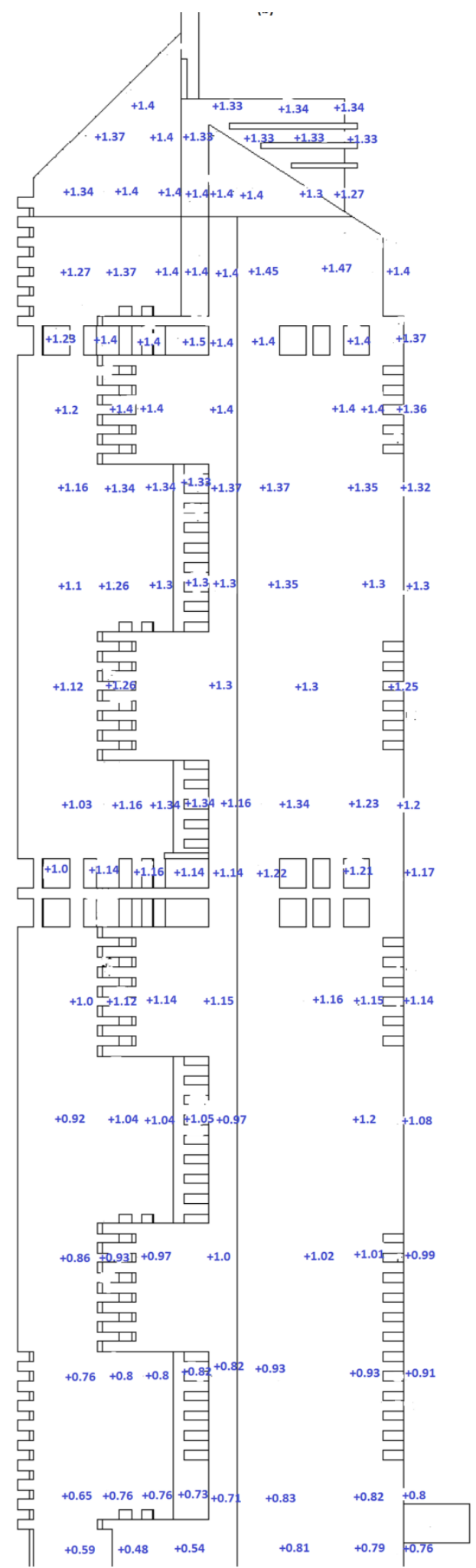

(b)

Fig. (12): Wind pressures in $\mathrm{kN} / \mathrm{m}^{2}$ on windward face of Blue Tower with wind directed in $0^{\circ}$ angle: (a) By wind tunnel testing; (b) By present CFD 


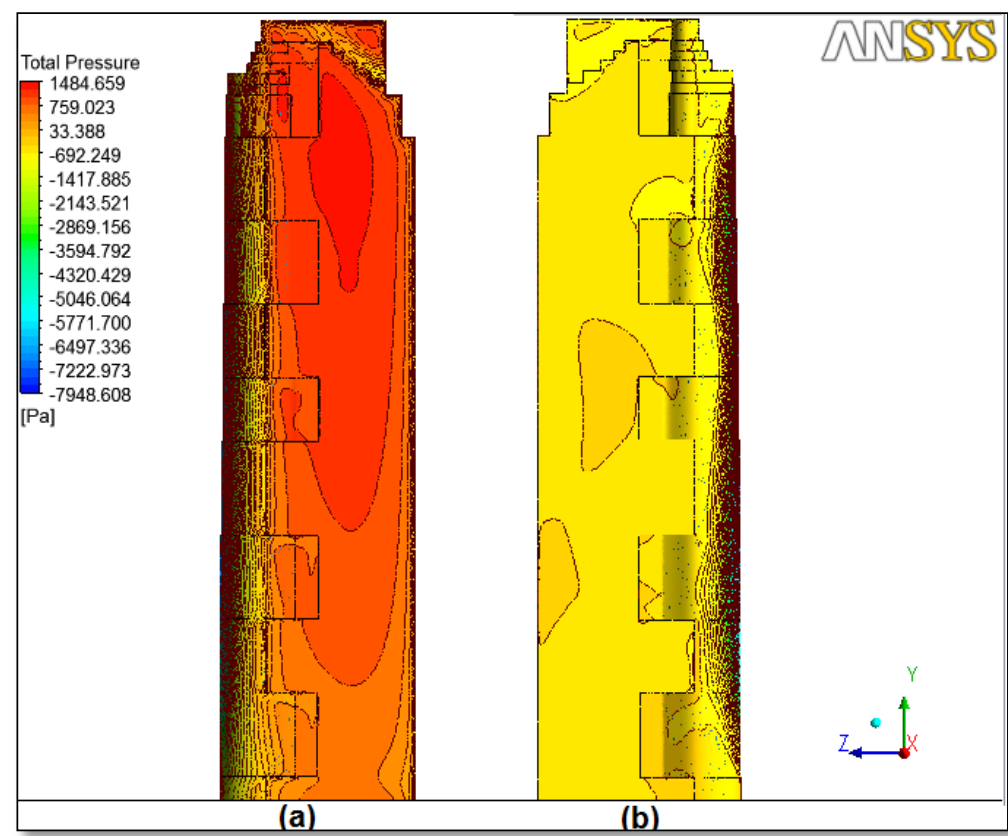

Fig. (13): Pressure countor lines on the building faces with wind directed in $0^{\circ}$ angle: (a) Windward face; (b) Leeward face

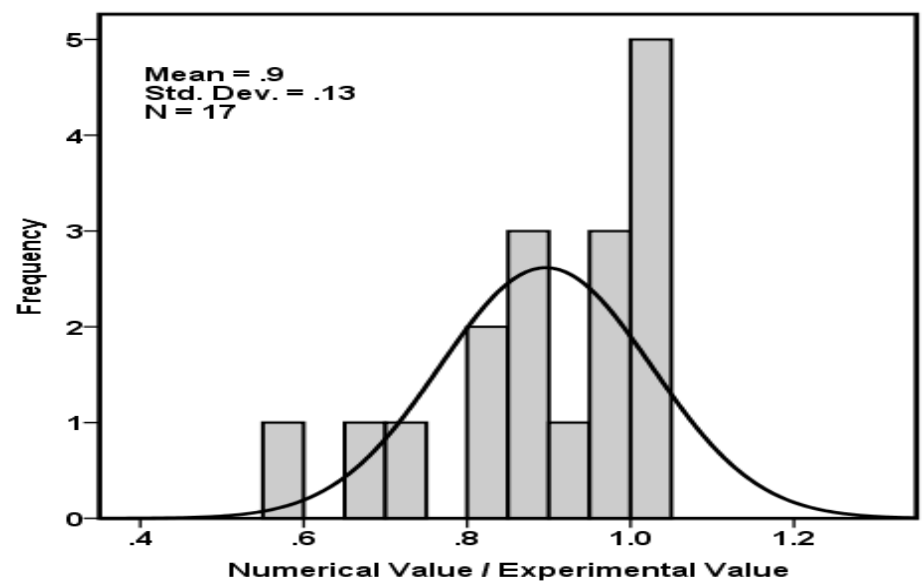

Fig. (14):Comparison between wind pressures of wind tunnel test and CFD analysis of Blue Tower at $0^{\circ}$ of wind direction

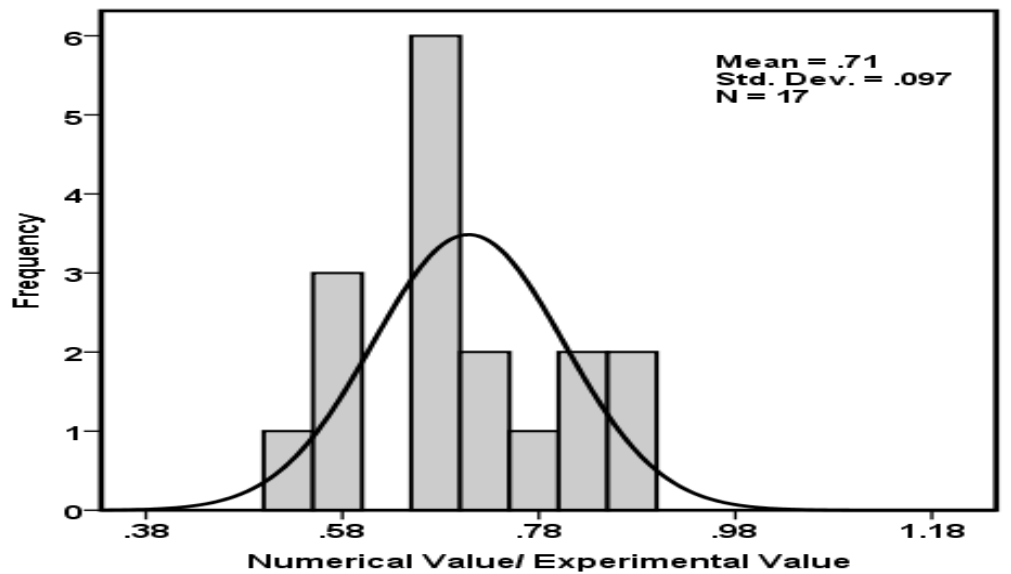

Fig.(15):Comparison between wind pressures of wind tunnel test and CFD analysis of Blue Tower at $90^{\circ}$ of wind direction 


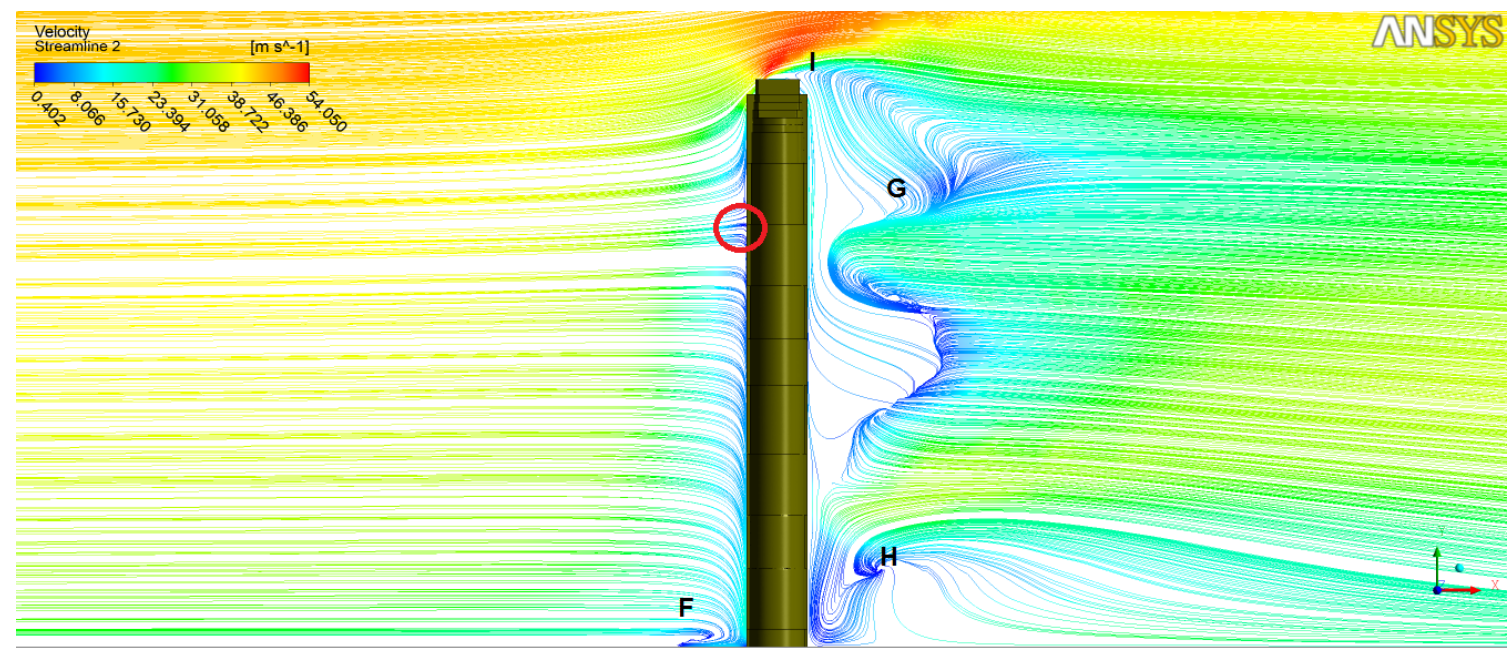

Fig. (16): The streamlines of wind velocity in the vertical center plane of wind over Blue tower

\subsection{Analysis Outputs for Rixos Hotel}

The values of the wind pressures on Rixos Hotel building were obtained by present validated CFD in ANSYS CFX 14.0. A conventional increasing in wind pressure is noticed over building surface in the upward direction as depicted in (Figure 17 to Figure 19). These outcomes are compared to international building codes findings (ASCE 2010; AS/NZS 2011; NBCC 2010; UBC 1997) . Based on the comparison results of total wind pressures at windward (front) and lee ward faces of buildings, good matching can be seen between present CFD and ASCE (2010) results. In Figure (20), the pressure distribution on the windward and lee faces of the building are provided and complied with the data given in (Figure 19). Air flow behavior around Rixos building shown in Figure 21 in CFD simulation is given also in terms of the wind speed streamlines at $5 \mathrm{~m}$ horizontal plane above the ground and in vertical plane at building center. It is observed that the stagnation point is occurred at height of $62 \mathrm{~m}$ from the ground surface. Present computational analysis results are displayed in two forms such as CFD verification and application outputs.

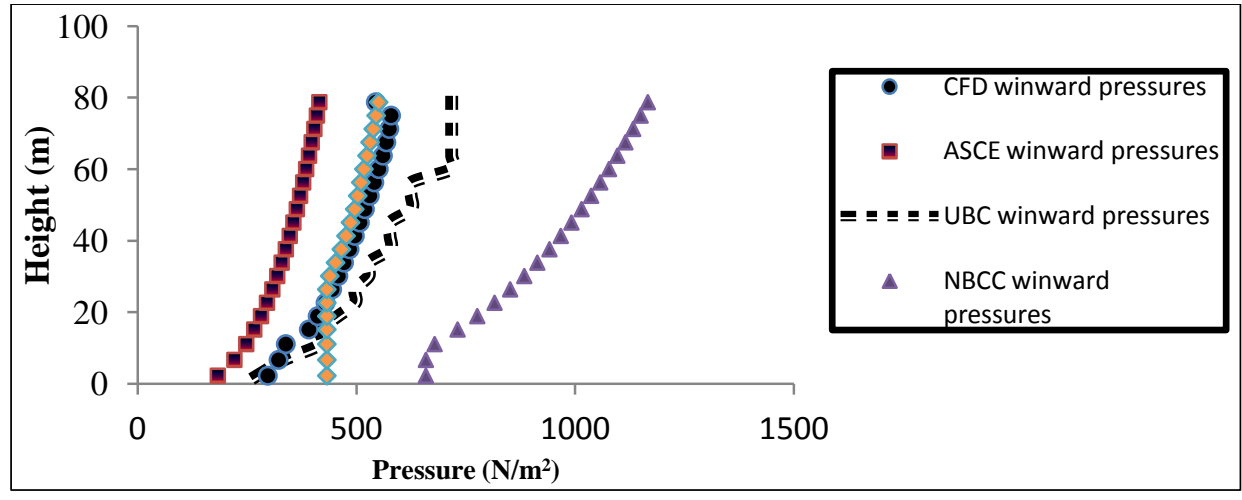

Fig. (17): Wind pressures distribution at windward faces of Rixos Hotel model 


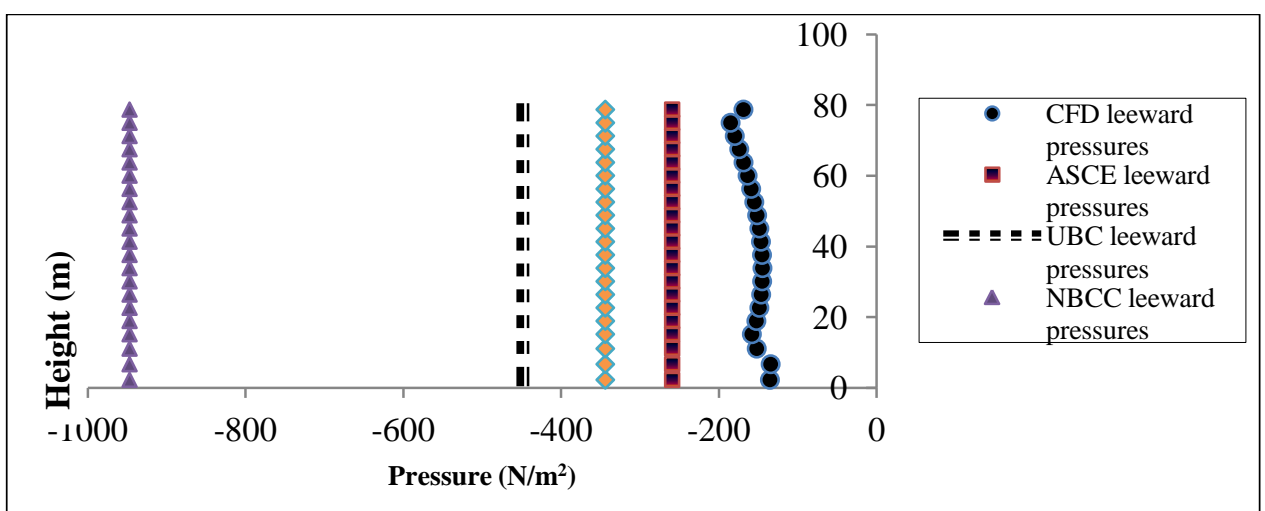

Fig. (18): Wind pressures distribution at leeward faces of Rixos Hotel model

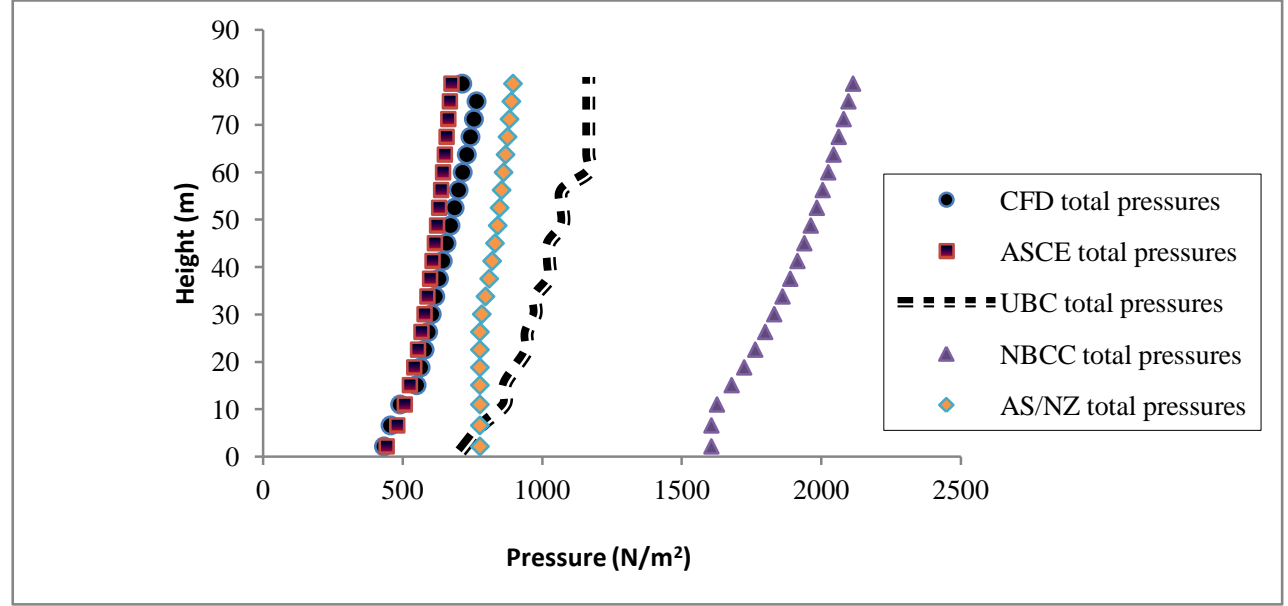

Fig. (19): Wind pressures distribution at windward and leeward faces of Rixos Hotel model

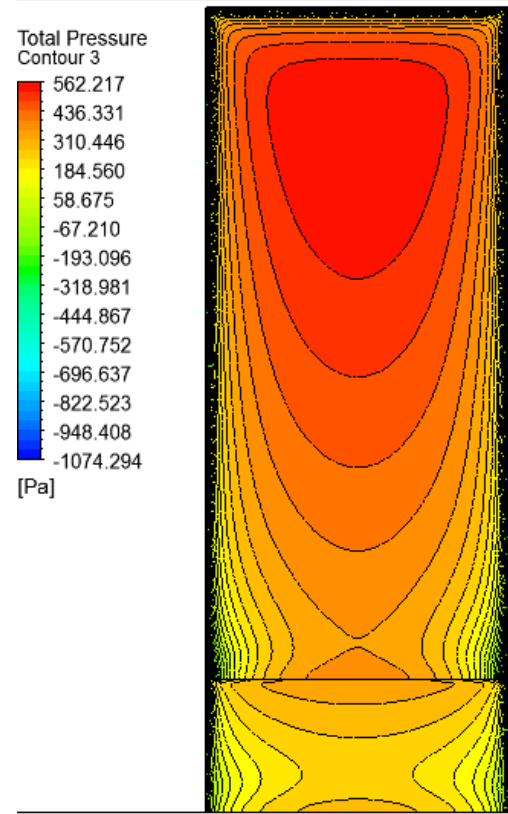

(a)

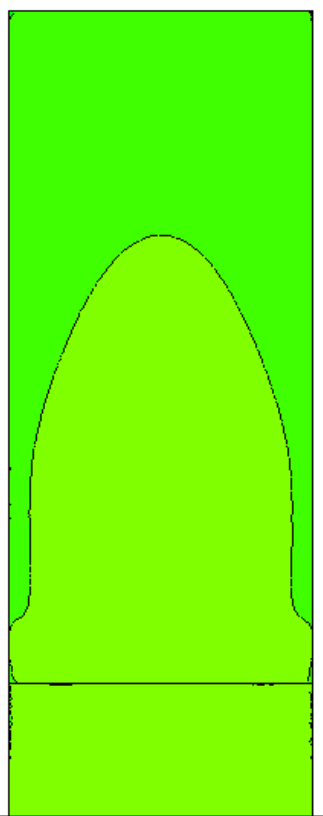

(b)

ANSTSS

Fig. (20): Contour lines of surface pressures on windward Rixos building in CFD simulation face of Rixos :

(a) Windward face; (b) Leeward face 


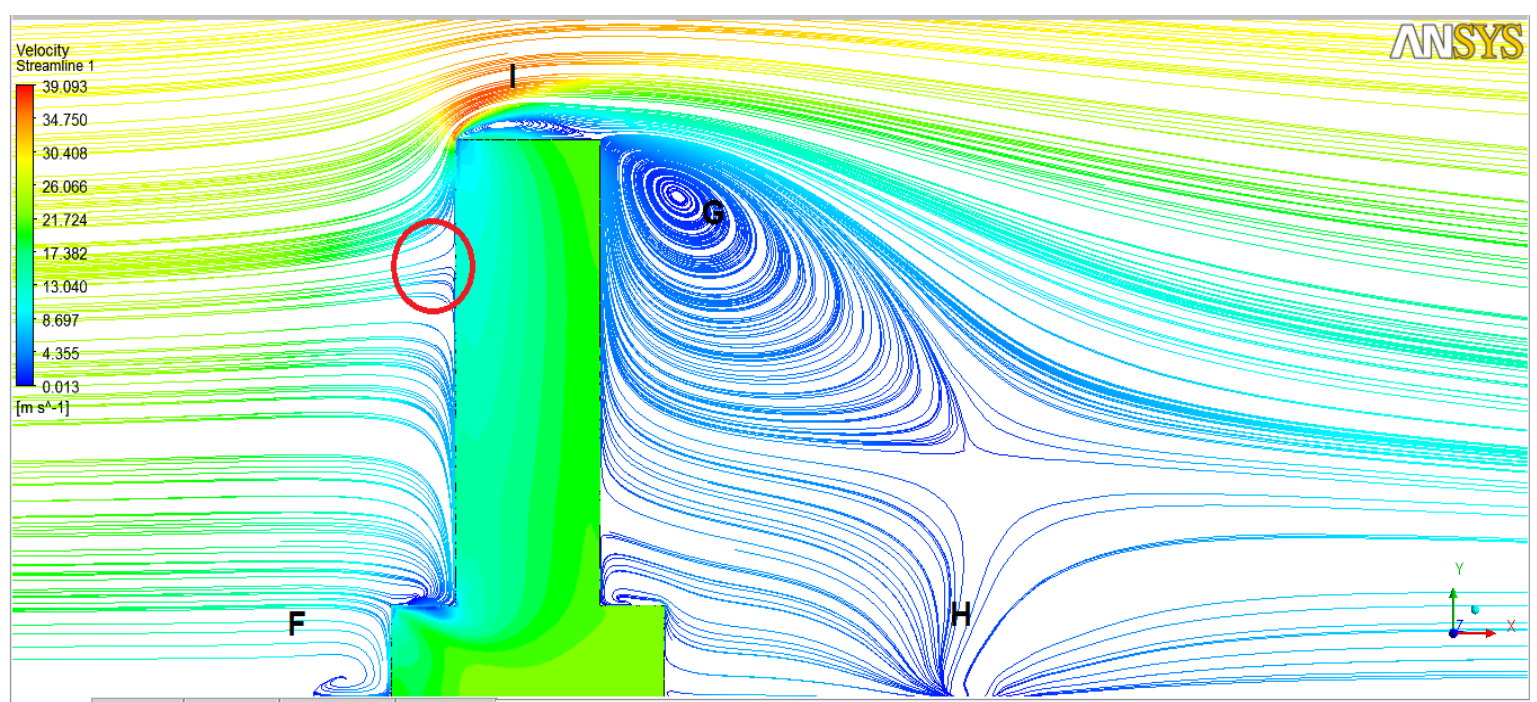

Fig. (22): The Streamlines of wind velocity in the vertical center plane of wind over Rixos building

\section{CONCLUSIONS}

The values of the wind pressures on Rixos Hotel building were obtained by present validated CFD in ANSYS CFX 14.0. A conventional increasing in wind pressure is noticed with dependence on the present simulation findings and conclusions are given as hereunder:

1. Present 3D steady CFD simulation approach can be utilized as an alternative method for costly wind tunnel approach with reasonable correlation coefficient for simulation of wind flow around irregular buildings.

2. The streamline velocity of wind flow in CFD simulation at two thirds of the building height comes to rest and forms the stagnation point.

3. ASCE criteria for wind pressure measurements are matching with CFD simulation outcomes of wind analysis for concrete high buildings located in Duhok city.

\section{REFERENCES}

- American Society of Civil Engineers ASCE. (2010), Minimum design loads for buildings and other structures. Journal of Wind and Structures, Vol. 14, No. 1, pp. (15-34).

- ANSYS-CFX Help, Release 14.0. (2011): http://www.ANSYS.com.

- Australian/New Zealand Standard (AS/NZS), (2011), Structural design actions Part 2: Wind actions, Joint Technical Committee BD-006, Australia/New Zealand.

- Baetke, F., Werner, H. and Wengle, H. (1990), Numerical Simulation of Turbulent Flow over Surface-Mounted Obstacles with Sharp Edges and Corners, Journal of Wind Engineering and Industrial Aerodynamics, Vol.35, pp. (129-147).

- Baskaran, A. and Kashef, A. (1996), Investigation of Air Flow Around Buildings Using Computational Fluid Dynamics Techniques, Journal of Engineering Structures, Vol.18, pp. (861-875).

- Behrouzi, F., Che Bin Sidik, N. A., Abdul Malik, A. and Nakisa, M. (2014), Prediction of Wind Flow Around High-Rise Buildings Using RANS Models, Applied Mechanics and Materials Vol. 554, pp. (724-729).

- Blocken, B., Stathopoulos, T., Carmeliet, J. (2007), CFD simulation of the Atmospheric Boundary Layer: Wall Function Problems, Atmospheric Environment, vol.41, pp. (238-252).

- Blocken, B., Stathopoulos, T., Carmeliet, J. and Hensen, J. (2011), Application of CFD in building performance simulation for the outdoor environment: an overview, Journal of Building Performance Simulation, Vol. 4, No. 2, PP. (157-184).

- Dagnew, A.K., Bitsuamalk, G.T., Merrick, R. (2009), Computational Evaluation of Wind Pressures on Tall Buildings, 11th America's conference on wind engineering.

- Duhok Rixos Hotel,(2012), http://kurdistanskyscrapers.com/topic/8299472/ $\underline{1 /}$

- Dyrbye, C., Hansen. S.O. (1997), Wind Loads on Structures, John Wiley \& Sons, Ltd, Baffins Lane, Chichester, England.

- Farquhar, S., Galsworthy, J. (2008), A Study of Wind Effects for HHHR Tower, Dubai, United Arab Emirates.

- Ferziger, J.H. (1990), Approaches to Turbulent Flow Computation: Applications to Flow over Obstacles, Journal of Wind Engineering and Industrial Aerodynamics, vol.35, pp. (1-19). 
- Hu, Ch., Wang, F. (2005), Using a CFD approach for the study of street-level winds in a built-up area, Building and Environment, Vol.40, PP. (617631).

- Chand, I.,Bhargava, P. K.,Krishak, N. L. V.(1998), Effect of balconies on ventilation inducing aeromotive force on low-rise buildings, Building and environment,vol.33,1ssue(6), pp. (385-396).

- Cheung, J.C.K., and Melbourne, W.H., (1992), Torsional Moments of Tall Buildings, Journal of Wind Engineering and Industrial Aerodynamics, vol.42, issue 1-3, pp. (1125-1126).

- Jeong, W., and Seong, J.(2014), Comparison of Effects on Technical Variances of Computational Fluid Dynamics (CFD) Software Based on Finite Element and Finite Volume Methods, International Journal of Mechanical Sciences, Vol.78, PP. (19-26).

- Haleem, D. A., Kesserwani, G., and CaviedesVoullime, D. (2015). Haar waveletbased adaptive finite volume shallow water solver. Journal of Hydroinformatics. Vol. 17(6):857873

- Mendis, P., Ngo, T., Haritos, N., Hira, A., Samali, B., and Cheung, J. (2007), Wind Loading on Tall Building, EJSE Special Issue: Loading on Structures.

- Montazeri, H., and Blocken, B.J.E. (2013), CFD simulation of Wind-Induced Pressure Coefficients on Buildings with and without Balconies: Validation and Sensitivity Analysis, Building and Environment, Vol. 60, PP. (137149).

- National building code of Canada NBCC (2010), Associate Committee on the National Building Code, National Research Council (NRC).

- Nguyen, C. K., Ngo, T. D., Mendis, P. A., Cheung, J. C.K. (2006), Dynamic torsional behavior of tall building under wind loads using CFD approach, the fourth international symposium on computational wind engineering, Yokohama.

- Parv, B., Hulea,R., Mircea, Z.R. (2012), Comparative study of wind effects on tall buildings using international codes and CFD, European Congress on Computational Methods in Applied Sciences and Engineering (ECCOMAS).

- Paterson, D. A. and Apelt, C. J. (1986), Computation of Wind Flows Over Three-Dimensional Buildings, Journal of Wind Engine and Industrial Aerodynamics, Vol.24, Issue.3, PP. (193-213).

- Piradeepan, N. (2002), An Experimental and Numerical Investigation of a Turbulent Airfoil Wake in a 900 Curved Duct, Department of Mechanical Engineering, unpublished $\mathrm{PhD}$ dissertation, University of Brunel
- Ramponi, R. and Blocken, B. (2012), CFD Simulation of Cross-Ventilation for a Generic Isolated Building: Impact of Computational Parameters, Building and Environment, Vol.53, PP. (34-48).

- Richards, P. J., and Norris, S. E. (2011), Appropriate Boundary Conditions for Computational Wind Engineering Models Revisited, Journal of Wind Engineering and Industrial aerodynamics, Vol.99, Issue 4, PP. (257-266).

- Sevalia, J.K., Desai, A. K. and Vasanwala, S. A. (2012), Numerical Evaluation of Wind Pressure on Surfaces of Bluff Body, International Journal of Engineering Research and Applications (IJERA), Vol. 2, Issue 1.

- Stathopoulos, T. and Zhou, Y. S. (1995), Numerical Evaluation of Wind Pressures on Flat Roofs with the $(\mathrm{k}-\varepsilon)$ Model, Building and Environment, Vol. 30, No. 2, PP. (267-276).

Skyscraper center (2010) -

http://skyscrapercenter.com/building/hhhrtower/428.

- Stathopoulos, T. and Baskaran, B. A. (1996), Computer simulation of wind environmental conditions around buildings, Engineering structures, Vol.18, No.11, pp.876-885.

- Tamura, Y. and Kareem, A. (2013), Advanced Structural Wind Engineering, Springer Tokyo Heidelberg New York Dordrecht London.

- Taranath, B. S. (2012), Reinforced Concrete Design of Tall Buildings, CRC Press, Taylor and Francis Group.

- Tominaga,y., Mochidab, A., Yoshiec, R., Kataokad, H., Tsuyoshi, T., Yoshikawaf, M., and Shirasawa,T. (2008), AIJ Guidelines for Practical Applications of CFD to Pedestrian Wind Environment Around Buildings, Journal of Wind Engineering and Industrial Aerodynamics, Vol.96, Issue 10-11, PP. (17491761).

- Uniform Building Code UBC (1997), Structural Engineering Design Provisions, Volume 2.

- Yahyai, M., Daryan, A. S., Ziaei, M., Mirtaheri, S. M. (2011), Wind effect on milad tower using computational fluid dynamics, The Structural Design of Tall and Special Buildings, Vol.20, PP. (177-189).

- Yakhot, V., Orszag, S., Thangam, A. S., Gatski, T. B., and Special, C. G. (1992), Development of Turbulence Models for Shear Flows by a Double Expansion Technique, Physics of Fluids, Vol.4, Issue .7 .Yujun, J., Huizhi, L., Boyin, Z., Fengrong, Z., Bin, L., and Jianguo, S. (2008), Wind Flow and Wind Loads on the Surface of a Tower Shaped Building: Numerical Simulations and Wind Tunnel Experiment, Science in China Series. 